\title{
Água: a escolha da ciência
}

\author{
MARCIO MigUEL AUTOMARE I
}

\section{Início da crise hídrica}

$\mathrm{N}$

OSSO MUNDO vive muitas crises em suas necessidades vitais. A água é a principal crise que afeta a metrópole São Paulo e é decorrente, entre

muitos fatores, da sua governança. Mas se faz necessário situar localmente sua relação com o global, o que faremos a seguir.

O planeta possui alguns elementos fundamentais que convivem entre si: o ar, o clima, a água, a terra e os oceanos. Esses elementos não prescindem uns dos outros, em que pesem nossa arrogância, nosso descuido, nosso descaso. $\mathrm{O}$ mal uso de um desses elementos causa dificuldades e tragédias naturais. Sabemos que todos esses elementos estão afetados, sendo exauridos e usados sem critério pelo homem, colocando em risco nossa sobrevivência. O homem utiliza o estratagema filosófico de separar a ética da moral e assim explorar acima dos limites permitidos todos os recursos da natureza da qual faz parte, acreditando que nosso estágio científico lhe permite abusar do que é oferecido, pois imagina que a ciência encontrará a tecnologia necessária para resolver todos os nossos problemas ambientais.

Começamos por enfatizar que as mudanças climáticas somente são percebidas e sentidas no transcurso de milhares de anos. A história, depois da descoberta da escrita, tem cerca de três mil anos. Nossos saber e experiência comprovada com as questões climáticas e ambientais estão restritos aos últimos 150 anos, quando se inicia o acompanhamento de muitas das ocorrências na natureza (clima, terremotos, oceanos e atmosfera). Entretanto, o planeta Terra continua sua vida e seu processo evolutivo. Cientistas preveem em alguns milhares de anos, independentemente das nossas intervenções antrópicas, o que faremos, ou, pior, deixaremos de fazer, com respeito às necessárias mudanças no uso dos recursos naturais. Conforme preveem cientistas e climatologistas, no prazo de centenas de milhares de anos viveremos uma nova era glacial.

É necessário perguntar: quais foram nossas mais lamentáveis intervenções na natureza? Com certeza, primeiramente, o uso de florestas para geração de energia. Depois, a prática intensiva pela agricultura para produção de alimentos, e desde poucos anos, para os agronegócios (vegetal e pecuária). O intensivo uso de energias fósseis, com aproveitamento do carvão mineral e petróleo. Acredita-se que esse ciclo ainda dure mais alguns séculos, pois são grandes esses depósitos e já buscamos petróleo em altas profundidades oceânicas, como é a exploração do pré-sal. Nesse caso, não se pode deixar de dizer que remanescentes de florestas foram salvos, desde meados do século XIX, pelo uso da energia fóssil e pelo progresso do conhecimento cientifico dos últimos cinquenta anos. 
Não podemos deixar de citar as experiências com explosões atômicas em diversas regiões do planeta, até serem proibidos seus testes. ${ }^{1}$ Relacionamos os agressores e número de testes: Estados Unidos: 1.050; ex-União Soviética: entre 715 e 969; França: 210; Reino Unido: 45; China: 45; Índia: cinco ou seis testes; Paquistão: entre três e seis testes, totalizando 2.330 entre 1945/1998, quando foram proibidos. Em que pesem comprovados danos ao ambiente, à potência das bombas atômicas, esses milhares de testes não interferiram na órbita terrestre e não devem ser considerados como prováveis causas nas mudanças climáticas.

Não podemos negar que essas intervenções antrópicas, com uso perdulário das reservas de petróleo, o grande salto tecnológico desde a Segunda Guerra Mundial (1939/1945) com o uso de novas tecnologias, aumento da industrialização, a globalização da economia, o consumismo, trouxeram melhora das condições de vida para metade da população mundial. Mudanças nas transações internacionais, viagens aéreas, divisão do trabalho trouxeram a ilusão de que podemos ter tudo e que os recursos naturais são inesgotáveis. Não pretendemos um artigo de análises da economia, no entanto não podemos deixar de lembrar a nossa maneira de (produção de bens) buscar recursos naturais (matérias-primas), ligadas sempre a formas de exploração capitalista. Com certeza esses procedimentos mercantis aceleram a degradação ambiental e aumentam a fome e a pobreza do mundo.

Existe e prepondera um governo mundial, representado pela Organização Mundial do Comércio (OMC), que regula as transações entre países desenvolvidos, emergentes e subdesenvolvidos, e aos últimos reserva a penalidade do permanente atraso e pobreza. Um primeiro paradoxo, e são muitos, as nações do Sul (uma divisão entre países ricos no Norte e emergentes e pobres no Sul), não tendo condições de explorar seus recursos naturais desde o inicio da era capitalista, ainda preservam grande parte dos seus recursos naturais e sofrem assédio e saque, com estabelecimento de preços aviltantes no comércio das suas matérias-primas naturais (minério, petróleo e florestas).

A maneira de omitir essa abordagem tem sido responsabilizar prejuízos ocorridos na natureza, não considerando nosso passado de intervenções antrópicas, considerando que o fenômeno das mudanças climáticas possa ser enfrentado somente pela adoção de economia de baixo carbono e uso de tecnologia e superar os danos já causados pela exploração predatória e mercantil dos recursos naturais. As mudanças climáticas passam a ser o foco dos arranjos ambientais, relegando-se as necessárias mudanças socioeconômicas e as relações entre nações.

A presente crise hídrica na metrópole São Paulo pode causar dificuldades na nossa sobrevivência, mas não há risco de esgotamento do recurso natural água, ou a finitude desse recurso essencial à vida no planeta Terra. $\mathrm{O}$ risco existe e é grande, mas deve ser relacionado à insanidade da sociedade, que permite $\mathrm{e}$ suporta viver ausente do debate e da participação na gestão da sua cidade. Pontuamos a seguir nossas principais falhas: 
- Desperdício de água, sem controle no uso industrial e agrícola. Na região urbana, excesso de população em pequenas áreas. No Sistema Cantareira, só $4 \%$ da sua área é habitada (227.000 ha).

- Administramos mal os serviços públicos de distribuição de água e esgotos na metrópole São Paulo, onde $37 \%$ da produção de água potável são perdidos por vazamentos e "gatos".

- O adensamento da população e sua concentração em pequenos espaços, distante de fontes hídricas, exemplificando a cidade de São Paulo, onde dados revelam que dois terços da população moram em condomínios (prédios).

- Abordagem da educação escolar, abandonando a educação sexual, execrando as políticas públicas que preconizam o controle da natalidade e da autoestima da mulher.

- Destruímos as matas ciliares no entorno da grande capital São Paulo, permitindo a construção de moradias populares em áreas de mananciais e não cuidamos das reservas florestais necessárias para proteção desses mananciais.

- Não tratamos devidamente os efluentes. Nossos rios e córregos foram abandonados e tornaram-se depósitos de lixo. Esquecemo-nos de que grandes recursos financeiros foram destinados ao tratamento dos rios nas últimas décadas, sem explicações do porquê do aspecto calamitoso do rio Tiete.

- Permitimos anomalias industriais, implantação de grandes indústrias em áreas urbanas e de baixa oferta hídrica, como instalações de indústrias de bebidas, metalúrgicas e fábricas de tintas, grandes consumidoras de água, deixando de lado o necessário reordenamento social, econômico e geográfico dessas indústrias.

- Por comodidade, abandonamos o conceito do humano (no sentido do existir), deixamo-nos ser tomados pela ideia ultrapassada de que tão somente $\mathrm{o}$ individualismo e o consumismo podem governar o mundo. $\mathrm{O}$ mercado e $\mathrm{o}$ lucro resolvem nossas dificuldades, que tudo intitulado privado é superior ao interesse público.

\section{A origem da crise hídrica}

Por que países europeus (Norte) não passam por crises hídricas? Provavelmente em razão da gestão eficiente dos seus recursos hídricos. Quando examinamos os quadros de perda de água por vazamento: Brasil $=37 \%$; Estados Unidos $=16 \%$; Alemanha $=11 \%,{ }^{2}$ e citamos o Japão onde a perda por vazamento não ultrapassa $5 \%$, bem provável no devido momento de investimentos na renovação (troca de tubulação, material de qualidade) da rede de distribuição de água e esgoto, fica difícil considerar boa a eficiência administrativa da gestão das águas em São Paulo. O absurdo são as justificativas, pois sabemos e é noticiado o trabalho de manutenção, não deixando de supor que vazamento em níveis elevados corresponda à manutenção de empregos dos setores terceirizados. De qualquer forma, não se pode pretender eficiência, que seria menor aplicação de 
mão de obra, com o cenário de desemprego que ronda a economia brasileira, o que deixa a todos preocupados. Por tais justificativas e outras mais é que podemos afirmar que em hipótese alguma a "água está no fim".

No Brasil dizemos que a sociedade e os gestores privados dos recursos essenciais para a vida não consideram a escassez de muitos desses recursos; bem como, deixamos de considerar que a capacidade de resiliência de determinados recursos depende da manutenção das condições de seus entornos. Quando falamos da água não cuidamos de manter a paisagem em que se situam suas matas ciliares, e com certeza diminuímos as possiblidades de manutenção produtiva e dificultamos sua recuperação (resiliência). De forma irresponsável, crises e catástrofes ambientais são consideradas somente quando acontecem, motivo pelo qual essas questões não chamam a atenção da população.

Há 150 anos não havia preocupações com questões ambientais. Essas questões começam a ganhar corpo e sustentação científica desde o último quarto do século XX. Essa é a justificativa maior de os países do Norte não assumirem a responsabilidade pela degradação que vem desde o início do capitalismo industrial. Essa é a tônica em fóruns mundiais para discussão das questões ambientais, norteadas sempre na discussão das mudanças climáticas. Outras questões, que alcançam o viés do social e do acesso ao bem-estar mundial, ficam ausentes nesses encontros, preocupados exclusivamente em manter a hegemonia das nações desenvolvidas.

\section{A mercantilização dos recursos naturais no Brasil}

A privatização e a abertura do capital das empresas públicas de água e saneamento afastaram a administração pública de muito dos serviços que interessam diretamente à sociedade. No caso de água e esgotos, com a privatização ou transformação dessas autarquias em empresas de capital misto, o Estado abriu mão da responsabilidade de aplicar recursos obtidos com impostos recebidos, assumindo o papel de investidor, buscando viabilizar seu lucro nas ações que detém, pelo poder constitucional, criando agência de regulação dentro do seu aparelho gestor. Deixa de investir diretamente impostos e passa a esperar pelo lucro das ações que possui na empresa, que detém maioria das ações. Acontece eventualmente que esse lucro de investidor (no caso, o Estado) serve para financiar outras necessidades da sua administração e não as dos setores ligados à empresa na qual foi aberto o capital.

O Estado tem o poder democrático de escolher suas opções, quase sempre representando um grupo hegemônico para governar a sociedade numa determinada época. Depois de serem escolhidos para governar, esses representantes eleitos deixam de cumprir o prometido. A sociedade na verdade não espera muito, suas necessidades são poucas, mas essenciais: água, saúde, educação, moradia, segurança, transporte e trabalho. Entretanto, terminada a eleição a sociedade afasta-se e os governantes sentem-se seguros e não são cobrados por suas decisões, que atendem às determinações da sua organização partidária. 
Vivemos de acordo com a ideologia neoliberal, inaugurada por Margareth Thatcher na década de 1970, que implantou as reformas que julgou necessárias para modernizar a economia inglesa, promovendo a diminuição do Estado e abandonando a tese do bem-estar social. Vivíamos o período chamado "guerra fria", que prevalecia no mundo desde o final da Segunda Guerra Mundial, com a coexistência nem sempre pacífica entre o comunismo e o capitalismo, dois modelos distintos de governar a sociedade. Do nosso lado, mundo ocidental, prevalecia o liberalismo econômico, antecedente do neoliberalismo, a doutrina da economia clássica, recorrente da "mão invisível", como reguladora do mercado. Do outro lado, na antiga União Soviética prevalecia o chamado planejamento centralizado. Desde 1989, com a queda do Muro de Berlim, tudo mudou e prevalece hoje a ideia de que a iniciativa privada e o Estado mínimo, com funções de regulador dos direitos dos cidadãos e do mercado, funcionam melhor e vai funcionar por mais muitos séculos. Entretanto, em determinados setores da economia, chamados de sociais, e também no setor de infraestrutura, o setor privado não tem interesse ou não tem o capital necessário, como é o caso do fornecimento de água e tratamento de efluentes, manutenção e preservação de microbacias, estradas, hospitais, aeroportos e portos. Nesse caso, o capitalismo não se sente constrangido em ir buscar recursos financeiros para investir no setor público, ao invés de se organizar e captar via impostos os recursos necessários para investir nos setores sociais e de infraestrutura.

No Brasil, até o golpe de 1964 e início da ditadura militar, vivíamos num país com população menor e com a total descentralização da administração de água e esgotos. Cada município se organizava de forma a captar água, distribuir e cuidar dos efluentes. Entretanto, em 1969, a ditadura militar criou o Plano Nacional de Saneamento (Planasa), ${ }^{3}$ inaugurando o monopólio dos recursos hídricos, quando a União oferece aos estados e municípios recursos do FGTS, desde que invistam $50 \%$ desses recursos (empréstimos de longo prazo) em Estações de Tratamento de Águas e Estações de Tratamento de Efluentes, dando início a um modelo de gestão que vai durar até 1990, sobrevivendo esse modelo sem alterações no formato e sem a esperada eficiência até o início do governo Fernando Collor, sendo então relegado, datando dessa época as primeiras orientações do Banco Mundial na direção do aprofundamento das privatizações dos serviços de água e esgoto em todo Brasil.

Qual foi a dinâmica dos governos estaduais e municipais desde a redemocratização em 1985, quando se encerra o período militar? Nada de novo, e sim seguir as regras inauguradas por Margareth Thatcher e por Ronald Reagan nos Estados Unidos, seguindo conselhos do economista Milton Friedman, ${ }^{4}$ mentor de todas essas mudanças violentas ocorridas pelo mundo no último quarto do século XX. Violência e tratamento de choque para diminuir o tamanho do Estado, apesar de merecer reverência a resistência de trabalhadores, lideres sindicais e governantes, que tombaram tentando resistir. 
Entre nós, por estranha coincidência, o projeto "Estado mínimo" se inicia nessa época, próximo do final da década de 1990, quando o governo Collor, depois das eleições presidenciais de 1989, inaugura um arremedo de "choque econômico", abandonando as estatais criadas por militares, mas sem força política para aprofundar mudanças, que virão a acontecer em governo seguinte, inaugurado por Fernando Henrique Cardoso, vencedor do pleito presidencial de 1994.

No dizer do falecido jornalista Aloysio Biondi $(2014)^{5}$, inicia-se um período de vontade incontrolável privatista. Empresas públicas (estatais) foram leiloadas, a preços irrisórios, maquiadas, saneadas e depois vendidas para investidores nacionais e internacionais. Autarquias e empresas estatais responsáveis por água e saneamento básico, situadas em grandes cidades, foram privatizadas ou transformaram-se em empresas de capital misto, vendendo ações na bolsa. Pequenas ou grandes prefeituras por todo Brasil fazem convênios, por meio das recém-instituídas Parcerias Público-Privadas (PPP), destacando-se no Brasil, nesse setor de água e esgoto, o grupo francês Suez.

\section{A população de São Paulo pode confiar na Sabesp?}

A Sabesp ${ }^{6}$ (Companhia de Saneamento Básico do Estado de São Paulo - 1973) sucede autarquias criadas desde o início do século XX, para atender a demanda de água dos bairros elegantes da cidade de São Paulo (região de Higienópolis e cercanias). O Sistema Cantareira foi projetado para captar e distribuir água tratada, abastecendo há quase cem anos uma cidade que não para de crescer, ${ }^{7}$ o que prenuncia novas crises hídricas.

O Sistema Cantareira, principal reservatório de água da metrópole São Paulo, descuidou desde sempre da preservação do seu entorno e das suas matas. O perímetro do Sistema Cantareira alcança $227 \mathrm{mil}$ ha e governos que se sucederam no passado deveriam preservar essas florestas (pertencentes ao bioma Mata Atlântica), protegendo nascentes, córregos e rios que abastecem o grande reservatório. De toda a Mata Atlântica existente na região até fins do século XIX, restam somente $42 \%$ de matas. Convém ressaltar que mesmo a rápida expansão urbana na região não ocupa mais de $4 \%$ da área total do Sistema Cantareira.

Faltou planejamento para manter as matas e propiciar a resiliência ${ }^{8}$ dos seus recursos naturais, pois o ecossistema foi destruído e permitiu-se a exploração sem levar em conta as condições ambientais. Houve e ainda há falta de preocupação dos governantes (de ontem e de hoje), que permitiram e ainda permitem fazendas de gado, pastos e plantio de eucalipto para produção de celulose, indústria excessivamente poluidora e que possui uma grande planta industrial de celulose na região. Caso houvesse intenção de recuperar suas matas, a recuperação da paisagem do Sistema Cantareira custaria cerca de R 1,5 bi e iria demorar mais de vinte anos. Ressaltamos que poucas inciativas de replantio de florestas deram certo no Brasil, exceto o Projeto de replantar a Floresta da Tijuca; devastada por séculos de extração de madeira, foi replantada com dez funcionários no início do século XX. 
É importante destacar o programa de privatização acelerado do governo Fernando Henrique Cardoso (1995), que deu início às privatizações de quase todas as empresas estatais ligadas à União, destacando os setores de siderurgia, ferrovias, mineradoras e telefonia. Também no estado de São Paulo, Sabesp, Comgás, CPFL e Eletropaulo foram privatizadas ou houve abertura do capital. Nesse contexto, o estado de São Paulo segue as orientação da União e inicia a aplicação do Programa Estadual de Desestatização (PED), ${ }^{9}$ aprovado pela Lei n.9.361 durante o governo Mário Covas. Com aplicação do PED, estima-se que o estado tenha arrecadado cerca de R $\$ 77,5$ bilhões para os cofres públicos, em valores reajustados pelo IGP-DI. Entretanto, conforme atesta a atual situação (2015), com alegada falta de recursos para investimentos, pouco mudou o endividamento do estado de São Paulo. A Sabesp, obrigada a distribuir lucros (o governo estadual recebe mais 50\% desses lucros), deixou de fazer, na época devida, investimentos necessários para evitar a crise hídrica (2014), diante do que não evitamos prever novas crises no futuro.

Pela eficiência e independência dos Comitês de Microbacias, descentralização da gestão dos recursos hídricos, hoje adotada no Brasil e à qual São Paulo se antecipou, ou seja, antes de tornar-se diretriz nacional, o estado de São Paulo já havia identificado e estabelecido dezenove microbracias, e hoje são 21 microbacias em todo o estado. Os comitês não possuem autonomia e recursos para atuar em suas microbacias, pois suas receitas estão relacionadas ao Fundo Estadual de Recursos Hídricos (Fehidro) ${ }^{10}$ e com recursos financeiros que recebem da Sabesp pela retirada de água dos rios e aquíferos que formam determinada microbacia. Na verdade existe uma péssima relação de custo benefício entre a venda da água e o valor pago pela Sabesp. A Sabesp, entre os anos 2007, 2008 e 2009 , acumulou um faturamento bruto de R $\$ 19,5$ bilhões, repassando apenas R \$ 47,7 milhões para comitês de microbacias; ou seja, coube aos 21 comitês de microbacias $0,24 \%$ do total faturado pela Sabesp naqueles anos. Esses valores representam muito pouco diante do muito que se tem de fazer para recuperar a sustentabilidade de diversos rios e matas ciliares no estado de São Paulo.

Outra questão que causou espanto na opinião pública do estado foi a publicação da relação de clientes preferenciais, de contratos especiais. Nessa questão parece-nos que prevalece a lógica do equilíbrio de mercado; ou seja, como a demanda da água é inelástica e sua comercialização é monopólio da Sabesp, não se entende por que beneficiar grandes consumidores, sabendo-se que grandes consumidores de água (indústrias e shoppings) não poderão encontrar outro fornecedor. Talvez exista ou já existiu entre os gestores da Sabesp a decisão de aumentar a oferta, pois não previam riscos de falta ou escassez de água, como aconteceu em 2014. Erraram seus prognósticos, mas não é inusitada a avaliação indevida, pois é dessa forma que funciona o mercado. Convém ressaltar que a relação de clientes firmes e especiais da Sabesp foi publicada por determinação judicial, pois a empresa trata desse assunto secretamente. Foi assim que a socie- 
dade cível tomou conhecimento dos grandes consumidores de água, beneficiados por preços diferenciados. ${ }^{11}$

Estimamos que São Paulo ultrapasse um milhão de ligações residenciais ${ }^{12} \mathrm{e}$ vem desses domicílios a maior receita da Sabesp com a comercialização da água. As residências são os maiores consumidores dos serviços de água e esgoto e também os clientes que pagam preços maiores por metro cúbico de água, e sem perceberem subsidiam os grandes consumidores.

Dessa forma, confirma-se a teoria econômica de que existe uma oferta inelástica de água na região e a oferta deve gerar lucro, e é o que faz a Sabesp; deixando de lado toda dimensão social, passa a interessar à Sabesp quem deixa maior resultado e lucro e não a melhoraria dos seus serviços. A água no modelo atual de mercado capitalista assume o papel de "bem econômico" e não "direito do cidadão".

No ano 2013, a Sabesp informou que os 500 maiores consumidores, chamados de "demanda firme", consumiram cerca de 24 bilhões de metros cúbicos de água, equivalente ao consumo de 110 mil famílias em um ano. Nossa crítica relativiza esses números, pois empresas e indústrias geram empregos, e pensar fechar essas empresas redundaria graves consequências sociais, com repercussões diretas na população mais pobre da cidade.

Uma pergunta, no entanto, merece ser respondida pela Sabesp: por que preços menores, pois se trata de monopólio (água) e esses consumidores não têm alternativa senão consumir da Sabesp? Convém notar que no consumo residencial, a tarifa por metro cúbico aumenta conforme aumenta o consumo. No caso do consumo industrial, acontece o contrário, diminui o preço à proporção que aumenta o consumo. São dois paradoxos e merecem atenção, sendo necessário cobrar coerência e adoção de fórmula que relacione diretamente, e não inversamente, o consumo e o preço por metro cúbico. Ao menos neste momento de crise, é necessário pedir transparência e não o segredo, com que agora esse assunto é tratado. A sociedade, os consumidores, todos merecem acompanhar todos os detalhes da gestão da crise.

A Sabesp possui em seus quadros 15 mil funcionários de carreira, para atender 363 municípios (incluindo a Região Metropolitana de São Paulo), que fazem parte do seu negócio. Além desses funcionários, possui número expressivo de funcionários terceirizados, para manutenção, leitura, obras, consertos etc... Infelizmente, entregar a funcionários terceirizados a responsabilidade por muitos serviços técnicos fragiliza a qualidade dos serviços. Por meio de comunicados à imprensa o Sindicato dos Trabalhadores em Água, Esgoto e Meio Ambiente do Estado de São Paulo (Sintaema) diz que é na área operacional onde a Sabesp mais aplica cortes de pessoal técnico. Talvez esteja aí nessa denúncia a resposta ao elevado percentual de vazamentos na metrópole São Paulo, que alcança cerca de $30 \%{ }^{13}$

Mesmo para os otimistas é difícil defender eficiência de gestão na Sabesp, quando fazemos uma análise crítica da sua atuação nestes últimos anos. Entre 
tantos desencontros de gestão, chama a atenção seus comunicados institucionais (Sabesp) apregoarem eficiência quando se perdem $30 \%$ da sua produção de água? Torna-se difícil encontrar justificativas e qualquer negócio fracassa quando passa a ter perdas elevadas na produção. Nesse quesito, a meta da Sabesp, de acordo com seus informes, é baixar esse índice de perdas para 26\% até 2020, o que indica continuar perdendo anualmente cerca $\mathrm{R} \$ 1,3 \mathrm{bi} \mathrm{em}$ receitas (cerca de $10 \%$ do seu faturamento anual).

\section{Qual é a escolha da ciência?}

No livro de Nobert Nordhaus (ainda não editado no Brasil) The allocation of energy resources, aprendem-se duas lições: primeiro, é difícil fazer previsões, especialmente sobre o futuro distante; segundo, às vezes as previsões devem ser feitas mesmo assim. ${ }^{14}$

Iniciamos com essas duas lições que deixam de ser consideradas por alguns cientistas e a responsabilidade por não insistirem junto aos governantes para adoção de suas conclusões. No dizer de José Eli da Veiga (2014, p.105), no livro O imbróglio do clima - 2014, existem características distintas entre os cientistas, como também são distintas suas abordagens e a forma como elas podem ser aplicadas. O principal grupo é "os que preferem agir como intermediários, oferecendo aos formuladores de políticas públicas e aos que decidem sobre elas todas as informações disponíveis sobre as possíveis opções de ação". Achamos uma postura correta e, pelo que vemos, adotada pela maioria dos cientistas; bem como, concordamos ser a postura do GT Água/IEA/USP. Percebemos entre esses pesquisadores a busca por opções que ajudem a entender causas, consequências e alternativas para enfrentar a crise hídrica que acontece na metrópole São Paulo. Porém é necessário ponderar que justificativas teóricas preponderantes no grupo contemplam as mudanças climáticas como causadoras da crise hídrica, e fica difícil dialeticamente considerar a causa de a atual crise hídrica ser debitada à governança ineficiente na gestão dos recursos hídricos. Talvez sem que se perceba, a opção pelas mudanças climáticas seja estimulada pelo apoio de organismos mundiais que adotaram desde 1992 o clima como causador de todas as crises. Os ambientalistas e defensores das mudanças climáticas convivem com deliberações, protocolos, convenções e acordos nunca cumpridos, realizados e patrocinados pela ONU. Todos esses encontros buscam achar uma solução sem sacrificar a globalização, os acordos comerciais, o progresso dos países hegemônicos, tentando contornar a provável escassez e falta de recursos naturais (matérias-primas), mesmo que isso cause imensos sacrifícios às futuras gerações.

Por que o crescimento, e podemos dizer recente, dessas preocupações? Desde que Jean-Baptiste Fourier em 1827 descobriu os gases de efeito estufa, durante 173 anos demoramos até o início da década 1990 para começarmos a buscar opções para evitar o colapso da espécie humana, sendo essas preocupações calcadas quase todas no aquecimento global. O fato é que os países que mais contribuem para esse cenário de excessivo consumo dos recursos naturais, causadores 
de elevadas taxas de emissão de gases de efeito estufa, dos riscos atômicos, postergam suas ações e não aceitam limitar seu crescimento e domínio econômico, pois não querem em hipótese alguma travar seu progresso e acumulação de riquezas.

No desenho atual das forças econômicas, prevalece a decisão de que não podemos fazer no curto prazo mudanças nos modos de produção industrial, de alto consumo de energia fóssil $\left(\mathrm{CO}_{2}\right)$ e que a humanidade deve confiar na ciência moderna, que no futuro de alta tecnologia vai nos oferecer opções para nossa escolha. Sabemos que prepondera a corrente que considera a administração das crises suficiente, não considerando o princípio da precaução, não avaliando devidamente riscos e as consequências socioambientais. Poucos mencionam que esses riscos foram percebidos há décadas e não foram considerados. A nossa geração governante (global) está deixando de forma irresponsável um pesado ônus para futuras gerações, que elas, sim, deverão adotar medidas drásticas para salvar nossa espécie, mesmo que por mais alguns milhares de anos. Recordemos a mensagem quase esquecida, mas necessária no mundo atual: não somos eternos e nossa espécie não vai durar milhões de anos.

Nossa intenção neste artigo é breve. Prezamos e tentamos ser econômicos no texto, pois as opiniões apresentadas já merecem aprofundamento de muitos cientistas. Quisemos enfatizar a existência da permissiva anuência da humanidade com os crimes que se perpetuam contra a natureza. $\mathrm{O}$ artigo não tenta criar uma tese e registramos sinteticamente nossas reflexões a respeito da ciência da natureza. Procuramos mostrar que estamos fazendo errado e que a humanidade pagará pelos erros do presente, sendo bem provável num futuro próximo.

No início do século XX, nenhum cientista previu os acontecimentos cem anos à sua frente. $\mathrm{O}$ próprio autor, há cinquenta anos, não conseguiu prever nada do desenvolvimento da ciência, de tecnologias, produtos do uso comum e dos acontecimentos políticos de hoje. Há cem anos, o Titanic afundou e esse acontecimento no raiar do século passado trouxe um relativo retardo no desenvolvimento tecnológico, logo superado em dois anos pela brutalidade entre os homens (eclosão da Primeira Guerra Mundial, 1914/1918). O mundo continua brutal, sem cuidados com seus semelhantes e com a natureza. Este é o âmago deste artigo sobre a crise hídrica.

\section{Notas}

1 Disponível em: <http://pt.wikipedia.org/wiki/Teste_nuclear>

2 Cf. Folba S.Paulo, Caderno Cotidiano, 6.3.2015.

3 Instituído em 1969, o Planasa começou a funcionar dois anos depois, quando passou a destinar recursos para os estados criarem suas próprias companhias de saneamento. Para isso, instituiu o Sistema Financeiro de Saneamento (SFS), gerido pelo Banco Nacional da Habitação (BNH). Para obter o financiamento, cada estado da federação deveria criar, com base em seus recursos orçamentários, um Fundo de Financiamento para Águas e Esgotos (FAE) e uma companhia estadual de saneamento (Disponí- 
vel em: <http://www.brazil.guide.com.br/port/economia/saneam/planasa/index. php>).

4 Mentor e guru do Estado mínimo, patrocinador de golpes de Estado por toda a América Latina, especialmente no Chile, onde assessorou o ditador Augusto Pinochet. Milton Friedman organizou e dirigiu a Escola de Chicago e na reeleição de Ronald Reagan aconselhou-o a cortar benefícios, ao que este respondeu: "Espera aí, Dr. Friedman, se eu fizer isso perco as eleições". Nesse caso o economista não foi ouvido.

5 Aloysio Biondi (1936-2000), jornalista econômico, fez em O Brasil privatizado, um relato cheio de incredulidade e indignação das privatizações ocorridas no Brasil no governo Fernando Collor e aceleradas no governo de Fernando Henrique Cardoso.

6Disponívelem:<http://site.sabesp.com.br/site/interna/Default.aspx? secaoId=505>. Resumo Histórico: <https://pt.wikipedia.org/wiki/Sabesp>.

7 Documentário de Caio Silva Ferraz, Luana de Abreu e Joana Scarpelini, Senac-SP, 2009 - Disponível em: <http://urbanidades.arq.br/2011/05/entre-rios/, https:// www.youtube.com/watch?v=Fwh-cZfWNIc $>$.

8 Nicholas Georgescu-Roegen - "A analogia - sem depósito, sem devolução - beneficia a visão da vida econômica do homem de negócios. Pois, quando se olha apenas para o dinheiro, tudo que se pode ver é que o dinheiro apenas passa de uma mão para outra: exceto por um acidente lamentável, o dinheiro nunca sai do processo econômico. Talvez a ausência de qualquer dificuldade em obter matérias-primas por parte daqueles países onde economias modernas nasceram e floresceram tenha sido mais uma das razões para que os economistas permanecessem cegos diante deste fator econômico crucial. Nem mesmo as guerras que estas mesmas nações lutaram pelo controle dos recursos naturais do mundo fizeram os economistas acordarem de sua madorra" (Água e alimentos, perspectivas para o século XXI, Marcio Automare).

9 Cf. Rafael Sampaio, Carta Maior, 24 ago. 2006.

10 Disponível em: <www.comitestb.sp.gov.br/index>.

11 Disponível em : <http://ep00.epimg.net/descargables/2015/02/12/4f2256ded74 57ad412a5d0de76cf5487.pdf>.

12 A Sabesp não disponibiliza o número de ligações de água e esgoto na cidade, dai nossa estimativa.

13 Cf. Folha S.Paulo, 21.1.2015 - Caderno Cotidiano "Brasil desperdiça 37\% da água tratada".

14 Paul Krugman: a Civilização no Cassino, Disponível em: <http://www.apn.org.br/ w3/index. php/77- economia-traduzida/6013-krugman-a-civilizacao-no-cassino $>$.

\section{Referências}

AUTOMARE, M. Água - futuro ameaçado. Revista Filosofia, São Paulo, 2012. A pegada ecológica da agricultura. Campinas: Unicamp, 2013.

BARBOSA, V. A última gota. São Paulo: Planeta, 2014.

BASTOS, R. K. et al. São Paulo - Subsídios à regulamentação do Reúso da Água no Brasil. Revista DAE, n.177, maio 2008. 
BIONDI, A. O Brasil privatizado. São Paulo: Geração Editorial, 2014.

CARMO, R. L. et al. Água virtual, escassez e gestão. Revista Ambiente e Sociedade, n.2, jul./dez. 2007.

CASTRO, J. E. Water Governance in the Twentieth-first Century. Revista Ambiente e Sociedade, n.2, jul./dez. 2007.

JORNAL UNICAMP, n.623 - 27.4.2015.

ROSA, A. V. Agricultura e meio ambiente. São Paulo: Atual Editora, 1998.

SOUZA, A. N. Licenciamento ambiental no Brasil sob a perspectiva da modernização ecológica. 2009. Dissertação (Mestrado) - Programa de Pós-Graduação em Ciência Ambiental, Universidade de São Paulo. São Paulo, 2009.

VANDANA SHIVA. Guerras por Água. São Paulo: Radical Livros, 2006.

VARGAS, M. C. O negócio da água. São Paulo: Annablume, 2005.

VEIGA, J. E. (Org.) O imbróglio do clima. São Paulo: Senac, 2014.

RESUMO - A ciência nasceu há muitos séculos, evoluindo permanentemente. Desde os anos 1950, ela se desenvolve aceleradamente, obrigando-nos neste início de século a fazer a escolha: de um lado, aceitar que são as mudanças climáticas causadoras dos impactos naturais que podem ser mitigadas por novas tecnologias, e, de outro, reconhecer que nossas intervenções na natureza foram guiadas por objetivo econômico e lucro, exigindo urgente mudança de nossos hábitos e comportamentos.

PALAVRAS-CHAVE: Água, Crise, Governança, Meio ambiente, Riscos.

ABSTRACT - Science started many centuries ago, progressing permanently. Since the 1950s it has been developing increasingly, obliging us, at the beginning of this century, to make a choice: to accept that the weather changes cause natural impacts which may be moderated by new technologies and, on the other hand, may recognize that our interventions in nature were guided by economic purpose and profit, demanding urgent changes in our habits and behaviors.

KEYWORDS: Water, Crisis, Governance, Environment, Risks.

Marcio Miguel Automare é graduado em Ciências Econômicas pela Universidade Federal de Juiz de Fora (1973) e mestre em Administração Financeira pela Fundação Getúlio Vargas (1984). Membro da Associação Scientiae Studia (USP), analista de Desenvolvimento Organizacional da Fundação Itesp e pesquisador associado ao Grupo de Pesquisa Filosofia, História e Sociologia da Ciência e da Tecnologia do Instituto de Estudos Avançados (IEA/USP). @ - marcioautomare@yahoo.com.br

Recebido em 22.6.2015 e aceito em 6.7.2015.

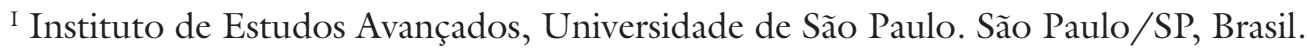

